\title{
Análisis de la ayuda oficial al desarrollo para servicios sociales básicos en el siglo XXI
}

\author{
YOLANDA MUÑNOZ OCAÑ̃
}

Departamento de Gestión empresarial y Métodos cuantitativos, ETEA-UNIVERSIDAD LOYOLA ANDALUCÍA, ESPAÑA. E-mail: yolandam@etea.com

\section{MERCEDES TORRES JIMÉNEZ}

Departamento de Gestión empresarial y Métodos cuantitativos, ETEA-UNIVERSIDAD LOYOLA ANDALUCÍA, ESPAÑA.E-mail: mtorres@etea.com

\section{RESUMEN}

Desde la década de los 90 hasta la actualidad, en pleno siglo XXI, importantes acuerdos internacionales (como el Consenso de Oslo 20/20 de 1996 y los Objetivos de Desarrollo del Milenio en el 2000) así como relevantes organismos internacionales relacionados con la cooperación al desarrollo, continúan insistiendo en la necesidad de erradicar la pobreza a través de la cobertura de las necesidades sociales básicas. Esta comunicación pretende analizar la contribución de la Ayuda Oficial al Desarrollo a la cobertura de las mencionadas necesidades en los países menos desarrollados durante la última década. Se trata de medir el grado de avance conseguido así como el camino que aún queda por recorrer.

Palabras claves: Desarrollo, servicios sociales básicos, ayuda oficial al desarrollo.

\section{Analysis of Official Development Aid for Basic Social Services in the $21^{\text {st }}$ century}

\begin{abstract}
Ever since the nineties and today in the $21^{\text {st }}$ century, significant international agreements (like The Oslo Consensus in 1996 and The Millennium Development Goals in 2000) and relevant international organisms related to development cooperation have been insisting on the need for a basic coverage of social needs to eradicate the poverty existing in the world. This communication aims to analyse the contribution made by Official Development Aid to meet this objective in less developed countries in the last ten years, and describes the progress that has been made in this field as well as the tasks that remain to be done.
\end{abstract}

Keywords: Development, Basic Social Services, Official Development Aid.

Clasificación JEL: F35, I31

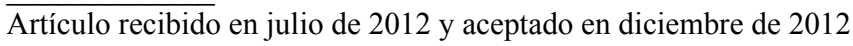

Artículo disponible en versión electrónica en la página www.revista-eea.net, ref. ə-30317 


\section{INTRODUCCIÓN}

Se ha definido el desarrollo humano como el proceso de ampliar las opciones a las personas. El objetivo del desarrollo debe ser permitir a las personas disfrutar vidas prolongadas, saludables y creativas. El principio básico que guíe la cooperación debe ser siempre colocar a personas en el centro del desarrollo y concentrarse en sus necesidades y en su potencial.

El análisis de las políticas de desarrollo y los resultados obtenidos a lo largo de la última mitad de siglo XX y la primera década del XXI ponen en tela de juicio el paradigma del crecimiento económico como único camino hacia el desarrollo, ya que, en muchas ocasiones, un aumento del Producto Interior Bruto sólo va acompañado de una distancia mayor entre ricos y pobres, debido a que la distribución de este crecimiento suele ser desigual, sin mencionar los desequilibrios medioambientales así como el agotamiento progresivo de cada vez más recursos que acompañan al crecimiento económico (Hicks and Streeten, 1979; McGillivray, 1991; Ravallion, 2000; Williamson, 2003; Vandemoortele, 2004, 2009; Barro, 2007). Es constatable que mientras que algunos países han conseguido progresar en el desarrollo social a pesar de un escaso crecimiento económico, otros países han registrado aumentos de los ingresos per cápita sin que se refleje ninguna mejora en los datos de pobreza o en las condiciones sanitarias de su población infantil.

"La lucha contra la pobreza será rápida y sostenible cuando se proporcione a las personas los medios para convertirse en agentes de su propio desarrollo (...) La cobertura universal de los servicios sociales básicos es clave para asegurar el crecimiento. Sin su cobertura universal, el círculo virtuoso del desarrollo social y económico seguirá siendo esquivo. Una vez que el acceso a un conjunto integrado de servicios sociales básicos de buena calidad se haga universal, el progreso social y el crecimiento económico podrán ser rápidos y sostenibles" (Vandemoortele, 2004).

Parece evidente que el progreso en un campo puede facilitar el progreso en los demás y esta interacción provoca sinergias que los gobiernos deben aprovechar para que el crecimiento económico avance junto al desarrollo humano (Fosu, 2010). En este ámbito, se observan dos sinergias que pueden ser complementarias: por un lado, existe una sinergia entre los SSB entre sí, es decir, entre las intervenciones en salud básica, salud reproductiva, educación, alimentación, agua y saneamientos, de tal manera que la intervención en cualquiera de los campos tendrá repercusión en el resto; por otro lado, existe una sinergia en la reducción de la pobreza, el desarrollo social y el crecimiento económico, de tal modo que las relaciones son de doble dirección: si es verdad que el crecimiento económico favorece (que no garantiza) la reducción de la pobreza y el desarrollo social, no es menos verdad que toda acción emprendida para reducir 
la pobreza y mejorar el desarrollo humano puede ser muy rentable en términos de crecimiento económico.

Por tanto, el mero crecimiento económico no es suficiente para alcanzar las cotas deseadas cobertura de necesidades básicas; alcanzar dichas cotas exigirá más recursos y un uso más eficaz de dichos recursos, lo que se traducirá en mejores servicios (agua, saneamiento, energía, transporte, salud y educación) que contribuyan, a su vez, a elevar las capacidades de los distintos pueblos que habitan la tierra y con ello, el desarrollo humano.

En la primera parte de este trabajo se analizará el papel que ha jugado la cobertura de las necesidades sociales básicas (NSB) en los principales acuerdos internacionales de cooperación para el desarrollo. Para ello se realizará una revisión, en orden cronológico y de materias, de los principales eventos y acuerdos internacionales desde la perspectiva de la cobertura de las mencionadas necesidades, así como los debates suscitados en torno a este tema. Posteriormente, se realizará un análisis estadístico descriptivo de la Ayuda Oficial al Desarrollo (AOD) concedida para mejorar los Servicios Sociales Básicos (SSB), evaluaremos el nivel de consecución de los compromisos adquiridos en los principales acuerdos internacionales previamente analizados y, finalmente, comprobaremos si el criterio de asignación de la ayuda responde a un modelo basado en las necesidades de los receptores.

\section{PRINCIPALES EVENTOS Y ACUERDOS INTERNACIONALES EN COBERTURA DE NECESIDADES SOCIALES BÁSICAS}

Una de las iniciativas que han marcado un punto de inflexión en la importancia de la cobertura de necesidades sociales básicas tanto a nivel nacional como internacional es la iniciativa 20/20, surgida en la Cumbre de Copenhague celebrada en 1995. No es la primera vez que se hablaba de necesidades sociales básicas en el marco del desarrollo humano y la erradicación de la pobreza. Son muchos los autores que han dejado constancia de la necesidad de satisfacer las necesidades básicas como condición necesaria, pero no suficiente, para el desarrollo, aunque es verdad que estas voces difieren en cuanto a la definición de cuáles son estas necesidades, así como en la concreción del método adecuado para llevar a cabo dicha satisfacción. Incluso existen claras divergencias en la nomenclatura utilizada para definir éstas necesidades (Muñoz, 2006), utilizando términos como "necesidades básicas", "necesidades humanas", "necesidades sociales", "derechos humanos", etc. (Viner, 1953; Seers, 1969; Stewart, 1985; Streeten et al, 1986; International Labour Organization 1976,1977; Sen, 1981, 
1999; Mahbub Al Haq, 1987; Nussbaum and Sen, 1993; Doyal and Gough, 1994; Max-Neef. et al, 1998; Nussbaum, 2007, 2012; Vandemoortele, $2004^{1}$ ).

Los Informes de Desarrollo Humano del Programa de Naciones Unidas para el Desarrollo (PNUD) nacen a principios de la década de los noventa y constituyen los cimientos de lo que sería el acuerdo final de la Cumbre de Copenhague, cumbre que sienta las bases para que los gobiernos, tanto donantes (países u organismos multilaterales que conceden ayuda) como socios (países que reciben la ayuda), adquirieran compromisos serios en materia de cobertura de necesidades sociales básicas a nivel internacional. En el Informe de 1991 se hace una recomendación a los gobiernos para que dirijan la mitad de sus gastos sociales hacia las prioridades humanas, llegando incluso a concretar dichos gastos por sectores (educación básica, salud básica, acceso a agua potable, eliminación de la malnutrición y acceso a la planificación familiar), lo que se concreta en el Informe del año siguiente (1992), en el que se recomienda comprometer al menos el $20 \%$ del presupuesto de la ayuda en "prioridades humanas".

Sería muy reduccionista afirmar que una población en la que la cobertura de los servicios sociales básicos estén garantizados ha llegado al pleno desarrollo humano, ya que hay facetas del desarrollo humano que escapan a los SSB (Veres, 2006), pero sería imposible afirmar que se ha llegado al desarrollo humano sin haber conseguido la cobertura mínima de las NSB en toda la población; por tanto, la cobertura de las NSB es una condición necesaria pero no suficiente para llegar al desarrollo humano. Así, una meta intermedia en el desarrollo humano debe ser garantizar el suministro de SSB y aunque existe un consenso general en este planteamiento, la realidad indica que el gasto público que destinan los países en desarrollo en materia de servicios básicos es claramente insuficiente para garantizar dichos servicios para todos. Por otra parte, aunque la mayor parte de estos recursos deberán provenir fundamentalmente de los presupuestos nacionales de los países en desarrollo, sería una tarea difícil, si no imposible, sin una cantidad adicional proveniente de la Ayuda Oficial al Desarrollo destinada a servicios sociales básicos (Mehrotra et al., 2000, Nussbaum, 2007, 2012).

Con el fin de paliar el déficit de inversión en SSB de los países en desarrollo y el déficit de atención a los SSB en la distribución de la AOD por parte de los donantes, en la Cumbre sobre Desarrollo Social, celebrada del 6 al 12 de Marzo de 1995 en Copenhague, los gobiernos alcanzaron un nuevo consenso y es entonces cuando surge la iniciativa $20 / 20$, por la que se pretende establecer un contrato entre países donantes y socios por el cual, el $20 \%$ del gasto público del

\footnotetext{
${ }^{1}$ Si bien no existe consenso universal sobre la concreción de las necesidades consideradas básicas, a efectos de análisis se considerará como servicios sociales básicos (SSB) la propuesta del CAD (Comité de Ayuda al Desarrollo) el 14 de junio de 1999 (OCDE,2006) detallada en el apartado 3 del presente trabajo.
} 
país socio y el $20 \%$ de la ayuda al desarrollo concedida por el país donante irán destinados a servicios sociales básicos. Con esta iniciativa se pretende, por un lado, reconducir la cooperación internacional hacia la cobertura de necesidades sociales básicas, y por otro, conseguir la implicación del presupuesto de los países en desarrollo, con el fin de conseguir sinergias derivadas del objetivo común de donantes y socios. Dicha iniciativa se concreta un año más tarde en Oslo, donde se firma el llamado "Consenso de Oslo sobre la iniciativa 20/20". Desde entonces, se han celebrado numerosas reuniones para evaluar lo conseguido hasta el momento, adquiriendo compromisos para adoptar nuevas iniciativas y constatando que no existe paridad en el grado de cumplimiento de la iniciativa (Hanoi 1998; Copenhague+5: Ginebra 2000, Nueva York, 2005; Yemen, 2010).

El mismo año que se celebra "Copenhague+5", en el año 2000, se celebra la Cumbre del Milenio, quizá la cumbre más importante en la historia de la cooperación internacional al desarrollo, donde los 189 países firmantes aprueban la Declaración del Milenio. Fruto de esta declaración surgen los conocidos Objetivos de Desarrollo del Milenio (ODM), cuyo cumplimiento supondrá grandes avances en la cobertura de las necesidades sociales básicas (Vandemoortele, 2004).

De los ocho objetivos, cinco de ellos tienen relación directa con la cobertura de necesidades sociales básicas (Erradicar la pobreza extrema y el hambre, lograr la educación primaria universal, reducir la mortalidad de los niños menores de 5 años; mejorar la salud materna; combatir el VIH/SIDA, el paludismo y otras enfermedades). A pesar de que la valoración de los ODM despierta opiniones muy diversas en cuanto a su contribución al desarrollo humano, es evidente que se han "colado" en todas las agendas de los actores de la cooperación internacional, movilizando a organismos internacionales, gobiernos, sociedad civil, sector privado y medios de comunicación, alcanzando un gran poder mediático en la opinión pública mundial. Una de las claves de su elevada repercusión es la concreción de cada uno de estos objetivos en unas metas particulares a alcanzar (medibles a través de indicadores), con unos plazos de ejecución determinados para cada una, y con un seguimiento permanente. Esto debería facilitar la medición del grado de consecución, y sin embargo, tampoco existe unanimidad en la valoración del éxito o fracaso de los mismos.

Según los últimos informes publicados hasta la fecha (Informe 2012: Objetivos del Desarrollo del Milenio del PNUD y el Banco Mundial), algunos objetivos se están logrando antes de la fecha fijada: se ha logrado la reducción de la pobreza extrema a la mitad en 2010; se ha reducido a la mitad el número de personas sin acceso a agua potable; la matriculación de niñas en educación primaria ha igualado a los niños y se ha acelerado la reducción de la mortalidad materna y de los niños menores de 5 años. Estos avances son claramente muy 
positivos, sin embargo, todavía millones de personas carecen de buenas condiciones de saneamiento y el hambre continúa siendo un desafío global, con cientos de millones de niños sufriendo desnutrición y retraso en el crecimiento.

Aunque en muchos países los ODM han contribuido a una reducción de la pobreza y a un aumento de la cobertura en servicios básicos, su principal debilidad es su globalidad, es decir, miden el progreso mundial, a nivel agregado, hacia los objetivos y no mide el logro individual por países, por lo que aquellos que partieron en desventaja en el año 2000, sobre todos los de África subsahariana, no están en condiciones de cumplirlos. En opinión de Vandemoortele (2010), aunque a 2010 había transcurrido el 70\% del tiempo y se habían logrado únicamente el $40 \%$, la mejora en su cumplimiento sería posible si se adaptaran a las circunstancias específicas de cada país. La moderación del optimismo también se deriva de que gran parte de los logros tienen mucho que ver con el avance de China (Unceta et al, 2012). Si bien las causas del posible incumplimiento de los ODM provocan división de opiniones, parece haber unanimidad en la opinión de que los ODM deben servir para analizar logros y aprender de los errores, con el fin de consensuar una agenda internacional post-2015 (Vandemmortele, 2011; Tezanos 2011, Unceta et al., 2012).

En consonancia con la reflexión anterior sobre la eficacia real de la ayuda como herramienta de desarrollo, con el comienzo del siglo XXI, la Comunidad Internacional ha celebrado numerosas conferencias encaminadas a evaluar la eficacia de la ayuda y a alcanzar acuerdos que propicien una ayuda cada vez más eficaz para el país socio (Roma, 2003, París. 2005; Accra, 2008; Busán, 2011) así como otros acuerdos en torno a la financiación de la ayuda (Monterrey, 2002; Doha, 2008). Estos acuerdos reconocen la necesidad de asegurar la eficacia de la ayuda al tiempo que se apoye la construcción del estado y el suministro de servicios básicos, sobre todo en aquellos estados más frágiles.

En paralelo a la celebración de las reuniones de alto nivel que daban lugar a la firma de estos acuerdos, el análisis de la eficacia de la ayuda ha dado lugar a numerosos estudios de distinta índole que, en lugar de arrojar luz sobre la cuestión, generan si cabe aún más ambigüedad sobre este tema. Los primeros estudios (de autores como Nurske o Rosestein-Rodan en los años 50-60) arrojan resultados optimistas; valoran la eficacia de la ayuda así como su capacidad para complementar las inversiones nacionales, generando crecimiento y con ello, ayudar al desarrollo. Parece haber acuerdo en los analistas sobre que la cantidad debe ser suficiente (Big push) lo que inspira el ya mítico 0,7\% (del PIB del donante a ayuda al desarrollo), con el fin de garantizar la cantidad necesaria que asegure la eficacia. Entre los 60 y los 80 autores como Singer, Griffin, Bauer y Friedman cuestionan la eficacia de la ayuda, presentando una visión muy pesimista, en la que ponen de manifiesto el carácter sustitutivo de la ayuda debido a su fungibilidad (desvío de la ayuda para el consumo). 
La mejora de herramientas estadísticas y de los datos disponibles en la década de los 80 permiten mejorar la calidad de los estudios y analizar las relaciones entre ayuda, inversión y crecimiento económico (implícita subyace la idea de que crecimiento económico es igual a desarrollo) llegando a conclusiones muy dispares: mientras que la mayoría de los estudios establecen una relación entre ayuda e inversión, no está tan clara la relación entre ayuda y crecimiento (Mosley, 1987; Hansen y Tarp, 2000). El nuevo siglo comienza con el trabajo de Burnside y Dollar (2000), paradigmático para el Banco Mundial por impregnar sus directrices a los países donantes, cuyas conclusiones indican que la fungibilidad de la ayuda, y por ende, su eficacia, está directamente relacionada con el marco institucional y las políticas del país receptor; por tanto, la ayuda debe ser selectiva e ir dirigida a aquellos países en desarrollo que demuestren un marco institucional estable y unas política adecuadas. Estas directrices abren el debate de la selectividad de la ayuda, generando adhesiones a los distintos modelos de asignación que coexisten en la actualidad (intereses del donante, necesidades del receptor, combinados, etc.) y poniendo sobre la mesa una realidad muy controvertida: ¿se deben abandonar a su suerte aquellos países con instituciones débiles o políticas inadecuadas, cuando generalmente son estos mismos países los que acogen la mayor proporción de personas pobres en el mundo? Pregunta difícil de responder donde aparecen argumentos morales, históricos, etc.

A partir de este trabajo, se multiplica la producción de análisis sobre la eficacia de la ayuda con resultados muy ambiguos, ya que mientras que autores como Devarajan y Acemoglu corroboraban la relación entre eficacia y fortaleza institucional del receptor, otros como Durbarry, Hansen y Tarp, Lensink y White llegan a resultados contrapuestos, en los que la ayuda es eficaz por si misma, independientemente de las condiciones del país receptor; asimismo aparecen estudios que incorporan nuevos factores posibles condicionantes de eficacia. Este debate sigue alimentado por personalidades pertenecientes a organismos internacionales como William Easterly, economista del Banco Mundial, y Jeffrey Sachs, exdirector del Programa de los ODM, con posturas aparentemente contrapuestas, pero que, respecto a la cobertura de necesidades básicas no son tan distantes. Easterly opina que se está gastando gran cantidad de dinero en ayuda que no sirve a las personas, que los ODM son más relaciones públicas que ayuda eficaz y defiende que existe una relación clara entre corrupción y desarrollo, por lo que no se debe ayudar a gobiernos corruptos ${ }^{2}$. Por su parte, Sachs, coincide con Easterly en que la ayuda debe y puede llevarse a cabo con la menor corrupción posible, pero afirma que la lucha contra la corrupción debe incluirse en los programas de ayuda, en lugar de excluir de la

\footnotetext{
${ }^{2}$ De hecho, en alusión a esta idea, en su libro "The White man's burden" (2006) indica que los africanos salgan de la pobreza es la carga del hombre blanco.
} 
ayuda a los países que la padecen. En opinión de Sachs hay que evitar el despilfarro, pero en la actualidad la cuantía de la ayuda es insuficiente para sacar a millones de personas de la pobreza, por lo que aboga por un gran esfuerzo inversor. No considera inmorales los modelos de asignación de ayuda que combinan los intereses del donante con las necesidades del receptor, y aunque no cree que la ayuda sea la panacea, hay numerosos casos que "si se aplica bien, funciona". A pesar de las distancias iniciales, Easterly admite que la ayuda es efectiva en áreas concretas y cuantificables, sobre todo servicios básicos, indicando que "dar más dinero puede (...) reducir la mortalidad infantil, expandir el acceso a agua potable, expandir la vacunación, la mejora sanitaria... La ayuda es efectiva, pero puede ser más efectiva si se concentra en áreas" (Soti1lo, 2011, anexo)

En nuestra opinión, el papel de los países receptores es fundamental en la eficacia de la ayuda, pero en muchas ocasiones la falta de voluntad política de los países donantes se traduce en cantidades de ayuda insuficientes, muy volátiles, que impiden acometer proyectos estables capaces de traducirse en coberturas de las NSB que propicien avances mayores en la senda del desarrollo, " $L a$ ayuda tiene que proporcionarse a cada país que la necesite, en una manera predictible y previsible dentro de una perspectiva a largo plazo, y en cantidades suficientes (...) y con asignaciones de ayuda no orientadas o moldeadas por spots publicitarios e intereses políticos a corto plazo de los principales países donantes" (Riddell, 2007)

El mundo ha cambiado radicalmente desde los comienzos de la cooperación al desarrollo, 60 años atrás; sin embargo, aún persisten la pobreza, la desigualdad y el hambre; dar respuesta a estos desafíos globales es esencial para asegurar la consecución de los ODM, no solo a nivel global sino también a nivel país, lo que a su vez implicaría acercarnos a la cobertura universal de las NSB. Aunque la cooperación internacional para el desarrollo ha logrado muchos resultados positivos, los progresos han sido dispares y no han tenido la suficiente rapidez ni los alcances requeridos. En este contexto de acuerdos y avances desiguales, creemos necesario analizar la situación de la cooperación internacional en de Servicios Sociales Básicos, con el fin de arrojar alguna luz sobre lo acontecido en la última década de cooperación al desarrollo en dicha materia.

\section{ANÁLISIS DESCRIPTIVO DE LA AOD INTERNACIONAL DESTINADA A SSB EN LOS ÚLTIMOS AÑOS}

El análisis cuantitativo que se ha efectuado sobre la AOD internacional destinada a SSB se ha basado en la definición acordada por el Comité de Ayuda al Desarrollo (CAD) en el Working Party on Statistics (WP-STAT) el 14 de Junio 
de 1999, según la cual se incluirían los siguientes sectores del Creditor Reporting System (CRS) como SSB${ }^{3}$ :

- Educación básica: incluye educación primaria, capacitación básica de jóvenes y adultos y educación primera infancia (CRS 112);

- Salud básica: que incluye atención sanitaria básica, infraestructura sanitaria básica, nutrición básica, control de enfermedades infecciosas, educación sanitaria y formación del personal sanitario (CRS 122);

- Políticas y programas de población y salud reproductiva: incluye política sobre población, atención salud reproductiva, planificación familiar, lucha contra enfermedades de transmisión sexual incluido el SIDA y formación de personal para población y salud reproductiva (CRS 130);

- Agua potable y saneamientos básicos (CRS 14030, 14031 y 14032);

- Ayuda multisectorial para SSB (CRS 16050).

Se ha utilizado la información contenida en la base de datos CRS de la OCDE disponible on line www.oecd.org/dac/stats/crs correspondiente al período 2000 a 2010, y la unidad de medida utilizada ha sido ayuda comprometida (commitments) o desembolsada (disbursements), según el caso, de AOD bilateral (la concedida país-país, es decir, de un país donante a un país socio), multilateral (la concedida a través de un organismo multilateral al país socio) y la total (que incluye ambas, bilateral y multilateral), todas expresadas en millones de USD constantes de 2009 (para así reflejar la evolución real de la ayuda, descontando los efectos de la inflación).

\subsection{Evolución de la AOD total}

Cuando se utiliza el término de AOD se puede hacer referencia a la ayuda comprometida por los donantes durante un período determinado, o a la que realmente han distribuido en dicha etapa. Puesto que los compromisos de ayuda adquiridos por los donantes pueden ser llevados a la práctica en varios años

\footnotetext{
${ }^{3}$ El DAC, CAD en español, sigue un sistema de clasificación de la ayuda según el sector de destino en el país receptor, los conocidos códigos CRS, los cuales utilizan un código de 5 cifras para indicar el sector o categoría al que se destina la ayuda. Las 3 primeras cifras del código representan el sector o la categoría a la que se destina la ayuda, las 2 últimas cifras del código CRS son secuenciales y suelen utilizarse para definir subsectores. El sistema CRS incluye los siguientes sectores: infraestructuras y servicios, salud, programas y políticas sobre población y salud reproductiva, abastecimiento y depuración de aguas, gobierno, sectores productivos, etc. Parte de la AOD no va destinada a un sector específico, son las contribuciones no distribuibles por sectores, a saber: ayuda en forma de suministro de bienes y programas generales de ayuda; actividades relacionadas con la deuda, ayuda de emergencia, costes administrativos de donantes, ayuda a ONGD etc. Si deseamos estimar el porcentaje de AOD que se dedica a un sector concreto debemos hacer referencia a la AOD total distribuible por sectores tal y como se acordó en el DAC Working Party on Statistics (WP-STAT) en 1999.
} 
consecutivos, suele ocurrir que en un determinado período la cuantía de ayuda comprometida no coincida con la realmente desembolsada. Analizaremos pues ambas partidas. El compromiso total de AOD por parte de los países donantes (un total de 23 países pertenecientes al CAD hasta el año 2010, e incluyendo a los Emiratos Árabes Unidos y Kuwait, países fuera del CAD) así como de los organismos multilaterales, prácticamente se ha duplicado en el período 2000 a 2010, pasando de 83744 a 163608 millones de USD, aunque durante el camino ha sufrido algunos altibajos, incluyendo reducciones en la ayuda (en el año 2007). La mayor parte de la AOD comprometida (72\%) es de origen bilateral, frente a la correspondiente a los organismos multilaterales, que se mantiene próxima al $28 \%$ en promedio durante la década analizada, por ello, la tendencia de la AOD total viene determinada por la de la AOD bilateral (Figura1). Si comparamos la tendencia de ambos tipos de ayuda (bilateral y multilateral) podemos detectar un comportamiento casi opuesto de ambas, cuando una crece la otra decrece, y viceversa, como si se efectuara una compensación entre ellas.

Si analizamos la AOD realmente desembolsada o distribuida en el período estudiado tenemos que restringir el período al 2002-2010 pues no hay datos disponibles de los dos primeros años (2000 y 2001). El porcentaje de cumplimiento (de la AOD desembolsada sobre la comprometida) sería del $89 \%$ del total de AOD (en el caso de la bilateral es del $88 \%$ y en el de la multilateral del $91 \%)$.

Figura 1

Evolución de los compromisos de AOD total en el período 2000-10

(en millones de USD)

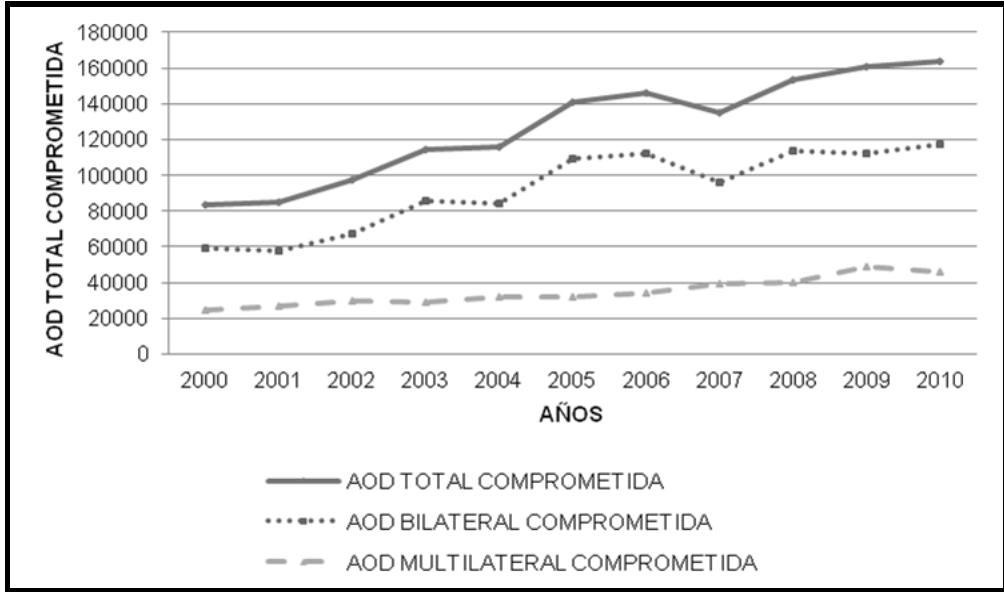

Fuente: Elaboración propia a partir de la base de datos CRS de la OCDE. 


\subsection{Evolución de la AOD destinada a Servicios Sociales Básicos (SSB)}

El análisis del cumplimiento del acuerdo $20 / 20$ por parte de los donantes se ha efectuado tanto para la ayuda comprometida como para la realmente distribuida, de esta forma comprobaremos si al menos en el ánimo del donante, con respecto a su compromiso, se cumple el límite del $20 \%$ y si, a su vez, este compromiso se materializa en la en la realidad con la AOD desembolsada para este fin.

La ayuda comprometida para SSB ha experimentado un crecimiento del $267 \%$ en el período, (superior al crecimiento de la AOD total, próximo al 200\% como se mencionó anteriormente) pasando de casi 9000, a más de 23000 millones de USD en el 2010 (Tabla 1).

Si nos preguntamos sobre el cumplimiento del acuerdo 20/20 establecido en el consenso de Oslo, en la parte que corresponde a los donantes (donar al menos un $20 \%$ de su ayuda para SSB) debemos considerar sobre qué partida calculamos la proporción, sobre la AOD total, o sobre la distribuible por sectores (según la codificación CRS), pues no está especificado en el acuerdo ${ }^{4}$.

Si consideramos como base la AOD total, el peso de la AOD para SSB habría oscilado entre el 10 y el $14 \%$ en el período analizado (Tabla 1). Si, por el contrario, consideramos como base la AOD distribuible por sectores, tal y como acordó el CAD posteriormente (OCDE, 2006), la proporción que ha supuesto la AOD para SSB sería mayor, oscilando desde un 15 a un $18 \%$ entre el año 2000 y 2010 , solo en un año del período, 2009, se alcanzó el 20\% (véase las celdas sombreadas en la Tabla 1). Si distinguimos el origen bilateral y multilateral de la ayuda, comprobamos que si bien, la primera supone una cuantía mayor en términos absolutos, en términos relativos está más alejada del cumplimiento del $20 \%$ que la AOD multilateral.

Si analizamos la AOD desembolsada para SSB entre los años 2002-2010, que ha oscilado entre el 70 y el $90 \%$ de la comprometida, comprobamos que durante los últimos 4 años del análisis se habría alcanzado el 20\% propuesto en el consenso de Oslo. Hay que resaltar que en los últimos años, a pesar de que la AOD total y la destinada a SSB aumentan, en términos absolutos, respecto al año anterior, la proporción de AOD para SSB ha disminuido respecto a los años anteriores.

\footnotetext{
${ }^{4}$ De la AOD total comprometida en la década estudiada (2000-2010), aproximadamente el $70 \%$ es distribuible por sectores.
} 
Tabla 1

Proporción de AOD comprometida destinada a SSB versus la AOD total y vs AOD distribuible sectorialmente. Período 2000-2010

(millones de USD)

\begin{tabular}{|cccccccccc|}
\hline Año & $\begin{array}{c}\text { AOD total } \\
\text { comprometida }\end{array}$ & $\begin{array}{c}\text { AOD } \\
\text { distribuible } \\
\text { por sectores }\end{array}$ & $\begin{array}{c}\text { AOD para } \\
\text { SSB }\end{array}$ & $\begin{array}{c}\text { \% AOD SSB } \\
\text { vs TOTAL }\end{array}$ & $\begin{array}{c}\% \text { AOD SSB } \\
\text { vs AOD } \\
\text { distribuible }\end{array}$ & $\begin{array}{c}\text { Bilat } \\
\text { SSB }\end{array}$ & $\begin{array}{c}\text { \% Bilat } \\
\text { SSB }\end{array}$ & $\begin{array}{c}\text { Multilat } \\
\text { SSB }\end{array}$ & $\begin{array}{c}\% \\
\text { Multilat } \\
\text { SSB }\end{array}$ \\
\hline 2000 & 83492,3 & 57927,9 & 8779,0 & $10,5 \%$ & $15,2 \%$ & 5983 & $15,4 \%$ & 2796,2 & $14,7 \%$ \\
2001 & 84710,4 & 59354,2 & 8676,6 & $10,2 \%$ & $14,6 \%$ & 5153 & $13,7 \%$ & 3523,7 & $16,3 \%$ \\
2002 & 97310,4 & 63538,7 & 9550,5 & $9,8 \%$ & $15,0 \%$ & 6823 & $16,7 \%$ & 2727,5 & $12,0 \%$ \\
2003 & 113835,7 & 69652,3 & 12076,9 & $10,6 \%$ & $17,3 \%$ & 7187 & $15,4 \%$ & 4889,4 & $21,3 \%$ \\
2004 & 115192,4 & 83307,9 & 14009,2 & $12,2 \%$ & $16,8 \%$ & 8804 & $15,5 \%$ & 5204,9 & $19,5 \%$ \\
2005 & 140636,7 & 83681,7 & 14999,8 & $10,7 \%$ & $17,9 \%$ & 9086 & $15,5 \%$ & 5913,7 & $23,6 \%$ \\
2006 & 146111,0 & 91825,1 & 18212,6 & $12,5 \%$ & $19,8 \%$ & 12375 & $19,1 \%$ & 5837,5 & $21,5 \%$ \\
2007 & 134390,7 & 99819,8 & 19504,7 & $14,5 \%$ & $19,5 \%$ & 12411 & $18,9 \%$ & 7093,7 & $20,7 \%$ \\
2008 & 152618,4 & 112897,9 & 21007,5 & $13,8 \%$ & $18,6 \%$ & 14594 & $17,7 \%$ & 6414,0 & $21,0 \%$ \\
2009 & 160143,4 & 123755,3 & 24900,6 & $15,5 \%$ & $20,1 \%$ & 16979 & $20,8 \%$ & 7706,1 & $19,1 \%$ \\
2010 & 163230,5 & 128751,6 & 23410,3 & $14,3 \%$ & $18,2 \%$ & 14243 & $16,1 \%$ & 9067,8 & $23,4 \%$ \\
\hline
\end{tabular}

Fuente: Elaboración propia a partir de la base de datos CRS de la OCDE.

\subsection{Distribución sectorial de la AOD concedida para SSB}

En el período analizado la AOD total desembolsada para SSB ha ido dirigida a Políticas y programas sobre población y salud reproductiva en primer lugar (40\%), seguida de Salud básica (29\%), Educación Básica (19\%) y en las últimas posiciones Abastecimiento y depuración de agua, sistemas menores (8\%) y Ayuda multisectorial a SSB (3\%). Este reparto es prácticamente igual al de la AOD bilateral, sin embargo la multilateral ha dedicado, prácticamente, la misma proporción a Población y Salud reproductiva que a Salud Básica; y a Multisectorial que a Agua y Saneamiento (Figura 2).

Esta distribución porcentual ha sufrido algunas variaciones en el período. Considerando la AOD total para SSB (incluyendo bilateral y multilateral) el peso del sector Población y Salud reproductiva ha crecido. Educación básica ha bajado y Salud básica se ha mantenido todo el período (Tabla 2).

Si consideramos la AOD bilateral, el crecimiento proporcional de la AOD para Población ha sido aún mayor, concentrando el 50\% de la ayuda en 2010. En este caso tanto Educación como Salud básica han disminuido su peso. En el caso de la AOD multilateral, el crecimiento de Población y Salud reproductiva ha sido más moderado, Salud básica ha subido su peso y Educación ha bajado. 
Figura 2

Distribución sectorial de la AOD desembolsada para SSB Imagen izquierda: $A O D$ bilateral / Imagen derecha: $A O D$ multilateral

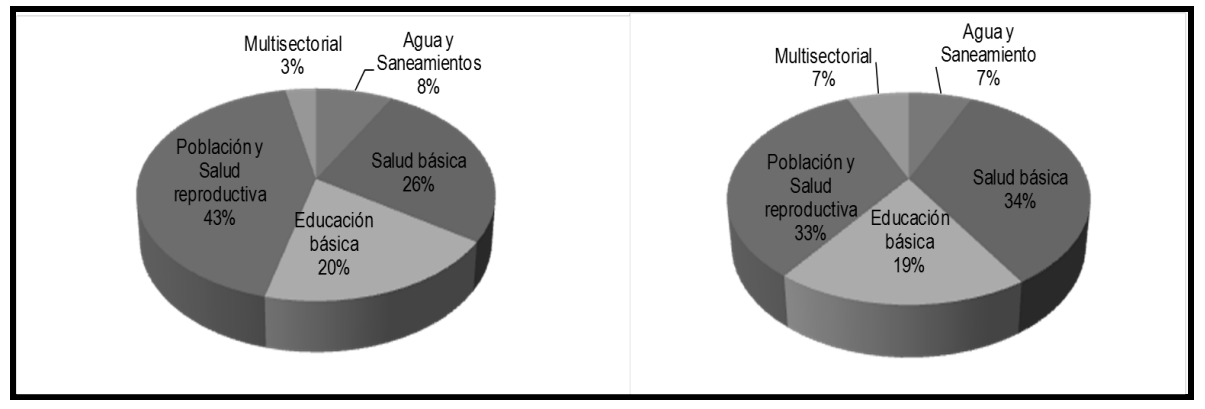

Fuente: Elaboración propia a partir de la base de datos CRS de la OCDE.

Tabla 2

Distribución sectorial de la AOD desembolsada para SSB 2002-2010 (millones de USD y \%)

\begin{tabular}{|c|c|c|c|c|c|}
\hline Sector & AOD total & $\begin{array}{c}\text { Promedio } \\
\text { anual }\end{array}$ & $\begin{array}{c}\text { Desviación } \\
\text { Típica }\end{array}$ & $\begin{array}{c}\text { Coeficiente } \\
\text { Variación }\end{array}$ & $\begin{array}{c}\text { Peso inicial y final } \\
\mathbf{2 0 0 2 - 2 0 1 0}\end{array}$ \\
\hline Agua & 9782 & 742 & 259 & $35 \%$ & $7-6 \%$ \\
\hline Salud Básica & 37853 & 2448 & 643 & $26 \%$ & $30-31 \%$ \\
\hline Educación básica & 25262 & 1811 & 566 & $31 \%$ & $23-17 \%$ \\
\hline Población y Salud reproductiva & 51104 & 3972 & 1934 & $49 \%$ & $33-45 \%$ \\
\hline Multisectorial & 5683 & 293 & 85 & $29 \%$ & $6-2 \%$ \\
\hline
\end{tabular}

Fuente: Elaboración propia a partir de la base de datos CRS de la OCDE.

Si analizamos la evolución de la cuantía, en términos absolutos, de la ayuda destinada a cada uno de los sectores incluidos como SSB, podemos afirmar que todos han seguido una tendencia creciente (Figura 3), como muestra la evolución de la AOD para SSB. Nótese que se trabaja con dos ejes por las diferencias de escala: el eje vertical primario (izquierda) para la AOD concedida a cada sector y el eje vertical secundario (derecha) para la AOD total destinada en total para SSB.

Para explicar la tendencia de la AOD total para SSB y por sectores se realizó un análisis de regresión, a pesar del reducido número de datos anuales disponibles sobre la ayuda desembolsada (2002-2010) y de las limitaciones que ello supone en la capacidad de generalización de los modelos. Se analizaron diversos modelos de ajuste (lineal, polinómico, exponencial y potencial) seleccionando finalmente aquellos que mostraron mayor bondad de ajuste $\left(\mathrm{R}^{2}\right)$ y cuyos coeficientes de regresión resultaron significativos (Tabla 3). La tendencia de la AOD para SSB, en total y por sectores, se ajustó bastante bien al modelo lineal. 
La de la AOD para Población se ajustó mejor al modelo exponencial en el caso de la AOD bilateral y al potencial en el caso de la multilateral. Salud básica también se ajustó a distintos modelos de tendencia según el origen de la ayuda. La AOD para Multisectorial sufre una gran variabilidad interanual, no mostrando ninguna tendencia en el período (los coeficientes de determinación fueron muy próximos a cero).

Figura 3

Evolución de la distribución sectorial y total de la AOD para SSB

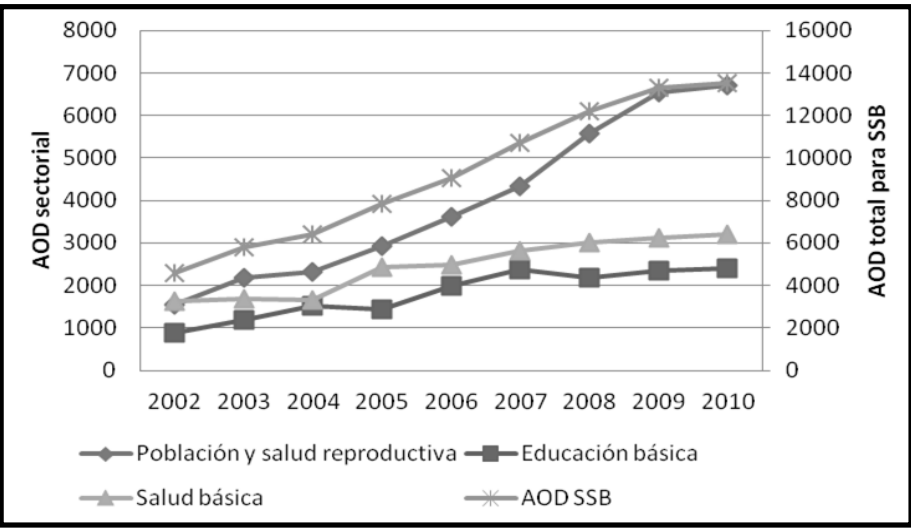

Fuente: Elaboración propia a partir de la base de datos CRS de la OCDE.

Tabla 3

Análisis de la tendencia de la AOD para SSB total y por sectores (2000-2009)

\begin{tabular}{|l|c|c|c|l|}
\hline \multicolumn{1}{|c|}{ SECTOR } & AOD & MEJOR MODELO & $\mathbf{R}^{2}$ ajustado & \multicolumn{1}{c|}{ Regresión } \\
\hline SSB & Total & Lineal & 0,989 & $4713,5+1934,7 \mathrm{t}$ \\
& Bilateral & Lineal & 0,985 & $3194,9+1214,4 \mathrm{t}$ \\
& Multilateral & Lineal & 0,957 & $1518,6+720,34 \mathrm{t}$ \\
\hline Población y Salud reproductiva & Total & Lineal & 0,984 & $1053,3+924,9 \mathrm{t}$ \\
& Bilateral & Exponencial & 0,981 & $1376,9 \mathrm{e}^{0,189 \mathrm{t}}$ \\
& Multilateral & Potencial & 0,951 & $708,02 \mathrm{t}^{0,567}$ \\
\hline Salud básica & Total & Lineal & 0,971 & $1092,5+622,67 \mathrm{t}$ \\
& Bilateral & Lineal & 0,920 & $1314,9+226,52 \mathrm{t}$ \\
& Multilateral & Exponencial & 0,959 & $368,83 \mathrm{e}^{0,2682 \mathrm{t}}$ \\
\hline Educación básica & Total & Lineal & 0,942 & $1510+259,94 \mathrm{t}$ \\
& Bilateral & Lineal & 0,88 & $833,5+195,7 \mathrm{t}$ \\
& Multilateral & Lineal & 0,491 & $676,54+59,276 \mathrm{t}$ \\
\hline Agua y saneamientos & Total & Lineal & 0,829 & $571,55+103,08 \mathrm{t}$ \\
& Bilateral & Lineal & 0,849 & $306,5+87,014 \mathrm{t}$ \\
& Multilateral & Lineal & 0,616 & $265,06+16,063 \mathrm{t}$ \\
\hline
\end{tabular}

Fuente: Elaboración propia a partir de la base de datos CRS de la OCDE. 


\subsection{Identificación de los principales donantes internacionales para SSB}

\subsubsection{AOD bilateral}

La primera cuestión que nos planteamos es si los países que donan mayor cuantía de AOD son también los principales donantes en materia de SSB, o si por el contrario, existe algún tipo de especialización de la ayuda para dicha finalidad. Además también resulta de interés analizar si los principales donantes son también los más comprometidos con la ayuda al desarrollo, para ello mediremos el grado de compromiso de los países donantes por medio del cociente de la AOD anual promedio del período (2000-2010), y el PIB del país (expresadas ambas partidas en millones de USD).

Como se refleja en la Tabla 4, el principal donante de AOD es Estados Unidos, con una aportación que supera al $26 \%$ del total de la ayuda donada por los países del CAD en el decenio 2000-2010. Le sigue Japón (16\%) y Alemania $(10 \%)$. Estos tres países concentran más del $50 \%$ de la AOD total. Si añadimos las aportaciones de Francia, Reino Unido y Holanda, llegamos al 75\% de la ayuda. España se encontraría en séptima posición en el ranking de AOD con una aportación de AOD del 3,4\%.

Con respecto a la cuantía de AOD concedida por los países para SSB (Tabla 4, Ranking cuantía AOD para SSB) el escenario es muy similar, con algunas alteraciones de orden pero poco significativas. En la cabeza figurarían los mismos países que en el ranking de AOD total, EEUU concentra el $45 \%$ de la ayuda, seguido de Reino Unido (10\%); Japón y Alemania (6\%, respectivamente) y Canadá (4\%). España se mantendría en séptima posición con una contribución de un $3,4 \%$ a la AOD total para SSB. Sin embargo, si ordenamos los países por la contribución porcentual de su AOD para la cobertura de NSB (Ranking por "especialización" en SSB) comprobamos que el ranking se modifica sustancialmente. Si bien continúan situados entre las primeras posiciones Estados Unidos, Canadá, Reino Unido, Holanda y España, ahora se sitúan a la cabeza Irlanda y Luxemburgo, países que estaban, sin embargo, ocupando las últimas posiciones en los rankings anteriores. Además, dichos países son los únicos del grupo de donantes del CAD que superan el umbral del $20 \%$ acordado en el consenso de Oslo (en promedio el porcentaje de AOD dedicada a SSB es del $11 \%$ para todos los países en el período 2000-2010). También destaca el caso de Nueva Zelanda, que estaba la última en el ranking de AOD total, y sin embargo, remonta a la sexta posición por su especialización en AOD para SSB así como Grecia, que pasa de la cola por su AOD total a la situación décimo primera por su especialización.

Por último, con respecto al grado de compromiso de los países con la AOD, los países que ocupan las primeras posiciones en este ranking son Holanda, Luxemburgo, Bélgica, Reino Unido y Francia. Destaca el caso de Japón, país a 
la cabeza por cuantía de AOD total y para SSB, y sin embargo a la cola en compromiso y especialización en SSB de su ayuda.

También merece la pena destacar la posición del principal donante, EEUU, pues en el ranking de compromiso se sitúa en una posición mucho más retrasada.

Tabla 4

Ranking países donantes según su contribución a la AOD total y para SSB

(millones de USD)

\begin{tabular}{|c|c|c|c|c|c|c|c|c|}
\hline $\begin{array}{c}\text { PAÍS } \\
\text { DONANTE }\end{array}$ & $\begin{array}{c}\text { AOD } \\
\text { TOTAL }\end{array}$ & AOD SSB & $\begin{array}{c}\% \\
\text { AOD } \\
\text { SSB } \\
\end{array}$ & PIB & $\begin{array}{c}\text { Ranking } \\
\text { AOD } \\
\text { total }\end{array}$ & $\begin{array}{l}\text { Ranking } \\
\text { cuantía } \\
\text { AOD SSB }\end{array}$ & $\begin{array}{c}\text { Ranking } \\
\text { especialización }\end{array}$ & $\begin{array}{c}\text { Ranking } \\
\text { compromiso }\end{array}$ \\
\hline Alemania & 97715,9383 & 6424,54514 & $7 \%$ & 2374500 & 3 & 5 & 17 & 7 \\
\hline Australia & 23048,1386 & 3042,30524 & $13 \%$ & 1284670 & 11 & 10 & 7 & 15 \\
\hline Austria & 9384,27427 & 261,649848 & $3 \%$ & 274818 & 16 & 21 & 22 & 9 \\
\hline Bélgica & 18737,873 & 1916,70358 & $10 \%$ & 340398 & 13 & 12 & 12 & 3 \\
\hline Canadá & 30686,3796 & 5044,4443 & $16 \%$ & 1528985 & 8 & 6 & 4 & 13 \\
\hline Corea & 5715,60067 & 505,340365 & $9 \%$ & 1065036800 & 19 & 18 & 15 & 23 \\
\hline Dinamarca & 18263,5288 & 1851,85422 & $10 \%$ & 1667839 & 14 & 13 & 13 & 19 \\
\hline España & 34015,3126 & 3842,17267 & $11 \%$ & 1047831 & 7 & 7 & 10 & 10 \\
\hline \begin{tabular}{|l|} 
Estados \\
Unidos \\
\end{tabular} & 264806,536 & 50819,4014 & $19 \%$ & 13863600 & 1 & 1 & 3 & 14 \\
\hline Finlandia & 7803,10477 & 590,112224 & $8 \%$ & 172518 & 17 & 17 & 16 & 6 \\
\hline Francia & 92755,5409 & 3343,26996 & $4 \%$ & 1889231 & 4 & 8 & 21 & 5 \\
\hline Grecia & 2316,45689 & 237,811456 & $10 \%$ & 231642 & 22 & 22 & 11 & 20 \\
\hline Holanda & 61628,7618 & 7598,04703 & $12 \%$ & 571145 & 6 & 3 & 8 & 1 \\
\hline Irlanda & 6093,26728 & 1270,54338 & $21 \%$ & 160597 & 18 & 14 & 1 & 8 \\
\hline Italia & 20222,769 & 984,542569 & $5 \%$ & 1519695 & 12 & 16 & 19 & 16 \\
\hline Japón & 157701,124 & 7036,0161 & $4 \%$ & 470936700 & 2 & 4 & 20 & 22 \\
\hline Luxemburgo & 2396,16856 & 497,166381 & $21 \%$ & 37393 & 21 & 19 & 2 & 2 \\
\hline New Zelanda & 2156,60441 & 329,217989 & $15 \%$ & 187802 & 23 & 20 & 6 & 18 \\
\hline Noruega & 28440,2918 & 3310,85518 & $12 \%$ & 2356599 & 9 & 9 & 9 & 17 \\
\hline Portugal & 4718,69679 & 95,687873 & $2 \%$ & 168504 & 20 & 23 & 23 & 12 \\
\hline Reino Unido & 69173,8732 & 11300,9152 & $16 \%$ & 1393854 & 5 & 2 & 5 & 4 \\
\hline Suecia & 25776,479 & 2326,14237 & $9 \%$ & 3105790 & 10 & 11 & 14 & 21 \\
\hline Suiza & 16707,3501 & 1008,82167 & $6 \%$ & 535650 & 15 & 15 & 18 & 11 \\
\hline TOTAL & 1000264,07 & 113637,566 & $11 \%$ & & & & & \\
\hline
\end{tabular}

Fuente: Elaboración propia a partir de la base de datos CRS de la OCDE.

Para analizar estadísticamente la relación entre los rankings efectuados se calculó la correlación lineal de Pearson existente entre ellos (Tabla 5), resultando significativa únicamente la correlación entre el ranking por AOD total y por cuantía de AOD para SSB $(0,936)$. Sin embargo, no existe una correlación 
significativa entre la especialización del país en AOD para SSB y los otros rankings. O sea, que los países que más donan coinciden con los que más aportan para SSB, pero no siempre con los que le dan más importancia a ésta partida dentro de su AOD, ni con los más comprometidos con la cooperación al desarrollo.

\section{Tabla 5}

Correlación entre diferentes rankings de países donantes de AOD

\begin{tabular}{|c|c|c|c|c|c|}
\hline Ranking & Estadístico & $\begin{array}{l}\text { Ranking } \\
\text { AOD total }\end{array}$ & $\begin{array}{l}\text { Ranking \% } \\
\text { de AOD país } \\
\text { a SSB }\end{array}$ & $\begin{array}{c}\text { Ranking } \\
\text { cuantía AOD } \\
\text { país a SSB vs } \\
\text { AOD total SSB }\end{array}$ & $\begin{array}{l}\text { Ranking por } \\
\text { compromiso }\end{array}$ \\
\hline \multirow{2}{*}{ Ranking AOD total } & Correlación & 1 &,- 016 & 936 & , 138 \\
\hline & Sig. (bilateral) & & ,943 &, 000 & ,529 \\
\hline \multirow{2}{*}{$\begin{array}{l}\text { Ranking \% de AOD país a } \\
\text { SSB }\end{array}$} & Correlación & & 1 & ,288 & , 164 \\
\hline & Sig. (bilateral) & & & , 183 & ,455 \\
\hline \multirow{2}{*}{$\begin{array}{l}\text { Ranking cuantía AOD país a } \\
\text { SSB vs AOD total SSB }\end{array}$} & Correlación & & & 1 & , 191 \\
\hline & Sig. (bilateral) & & & & ,383 \\
\hline \multirow{2}{*}{ Ranking por compromiso } & Correlación & & & & 1 \\
\hline & Sig. (bilateral) & & & & \\
\hline
\end{tabular}

Fuente: Elaboración propia a partir de la base de datos CRS de la OCDE.

\subsubsection{AOD Multilateral}

Si analizamos la AOD concedida para la cobertura de NSB por parte de los organismos multilaterales desde 2000-2010 (Tabla 6) podemos afirmar que los principales donantes han sido El Fondo Mundial de lucha contra el SIDA, la tuberculosis y la malaria; la Asociación Internacional para el Desarrollo (AID); la Comisión Europea, (European Institutions) y UNICEF. Se puede observar el cumplimiento de la regla de Pareto: el $20 \%$ de las organizaciones acumulan el $80 \%$ de la AOD multilateral para SSB.

\section{Tabla 6}

AOD comprometida para SSB por los organismos multilaterales (en millones de USD)

\begin{tabular}{|l|r|r|r|}
\hline \multicolumn{1}{|c|}{ ORGANISMO } & Total AOD SSB & $\begin{array}{c}\text { \% Acumulado } \\
\text { AOD SSB }\end{array}$ & $\begin{array}{c}\text { \% Acumulado } \\
\text { Organismos }\end{array}$ \\
\hline EI Fondo Mundial & 17825,53644 & $29,1 \%$ & $5,3 \%$ \\
\hline AID & 15454,06814 & $54,4 \%$ & $10,5 \%$ \\
\hline EU Institutions & 11410,61599 & $73,1 \%$ & $15,8 \%$ \\
\hline UNICEF & 3930,911835 & $79,5 \%$ & $21,1 \%$ \\
\hline UNFPA (Fondo de Población de las & 3483,463812 & $85,2 \%$ & $26,3 \%$ \\
\hline Naciones Unidas) & 2731,151269 & $89,6 \%$ & $31,6 \%$ \\
\hline GAVI Alliance &
\end{tabular}


Tabla 6 (continuación)

AOD comprometida para SSB por los organismos multilaterales

(en millones de USD)

\begin{tabular}{|l|r|r|r|}
\hline \multicolumn{1}{|c|}{ ORGANISMO } & Total AOD SSB & $\begin{array}{c}\text { \% Acumulado } \\
\text { AOD SSB }\end{array}$ & $\begin{array}{c}\text { \% Acumulado } \\
\text { Organismos }\end{array}$ \\
\hline UNRWA & 2166,993272 & $93,2 \%$ & $36,8 \%$ \\
\hline ONUSIDA & 1493,240525 & $95,6 \%$ & $42,1 \%$ \\
\hline Banco Asiático de Desarrollo (BAsD) & 1179,505926 & $97,5 \%$ & $47,4 \%$ \\
\hline Banco Africano de Desarrollo (BAfD) & 603,736862 & $98,5 \%$ & $52,6 \%$ \\
\hline Organización Mundial de la Salud (OMS) & 316,037068 & $99,1 \%$ & $57,9 \%$ \\
\hline Banco Interamericano de Desarrollo (BID) & 182,044101 & $99,4 \%$ & $63,2 \%$ \\
\hline $\begin{array}{l}\text { Programa de Naciones Unidas para el } \\
\text { Desarrollo (PNUD) }\end{array}$ & 161,547353 & $99,6 \%$ & $68,4 \%$ \\
\hline $\begin{array}{l}\text { Fondo de OPEC para el Desarrollo } \\
\text { Internacional (OFID) }\end{array}$ & 134,182521 & $99,8 \%$ & $73,7 \%$ \\
\hline $\begin{array}{l}\text { Fondo Internacional de Desarrollo Agrícola } \\
\text { (FIDA) }\end{array}$ & 57,811947 & $99,9 \%$ & $78,9 \%$ \\
\hline Banco Islámico de Desarrollo & 28,261072 & $100,0 \%$ & $84,2 \%$ \\
\hline $\begin{array}{l}\text { Fondo Árabe para el Desarrollo Económico } \\
\text { y Social (AFESD) }\end{array}$ & 7,530207 & $100,0 \%$ & $89,5 \%$ \\
\hline $\begin{array}{l}\text { Fondo de Naciones Unidas para la } \\
\text { construcción de Paz (UNPBF) }\end{array}$ & 7,235632 & $100,0 \%$ & $94,7 \%$ \\
\hline $\begin{array}{l}\text { Comisión Económica de Naciones Unidas } \\
\text { para Europa (UNECE) }\end{array}$ & $\mathbf{6 1 1 7 4 , 4 7 3 8 9}$ & $100,0 \%$ & $100,0 \%$ \\
\hline TOTAL & & & \\
\hline
\end{tabular}

Fuente: Elaboración propia a partir de la base de datos CRS de la OCDE.

\subsection{Identificación de los principales países receptores de AOD en SSB}

El análisis de la ayuda recibida por receptores se realizará evaluando el destino partiendo de la adecuación a un modelo de asignación de la ayuda basado en las necesidades del receptor, y no en los intereses del donante (Tezanos, 2008). La ayuda internacional, por tanto, se considera crítica para los programas de inversión en SBB y de lucha contra la pobreza (Vandemoortele, 2004).

Para determinar el grado de necesidad de los países receptores es necesario seleccionar un índice que determine qué posición ocupa el país en cuanto a cobertura de NSB. Puesto que las NSB incluyen diversos sectores, el índice debe abarcar el mayor espectro posible de los mismos, y a su vez, disponer de un número de datos suficiente que valide el análisis. A pesar de los problemas que plantean los índices agregados en cuanto a la selección de los indicadores parciales, cobertura incompleta del objetivo a medir, diversidad de métodos, etc. (Pena-Trapero, 2009), es necesario seleccionar uno para medir la cobertura de NSB en su conjunto. De los índices compuestos disponibles, hemos analizado el Índice de Desarrollo Humano (IDH) y el Índice de Capacidades Básicas por considerarlos representativos de la cobertura en NSB. El IDH está compuesto, a su vez, por tres índices: salud (medido por la esperanza de vida al nacer), edu- 
cación (medido por la tasa de matriculación y el porcentaje de alfabetización) y nivel de vida (medido por el PIB per cápita). Por su parte, el ICB lo componen tres indicadores: educación (porcentaje de niños que llegan a quinto grado), salud básica (mortalidad antes de cumplir los 5 años) y salud reproductiva (porcentaje de partos atendidos por personal especializado). Tras realizar un análisis comparativo de los dos índices se identificó una correlación lineal fuerte entre ambos $(0,886$ sig. $=0,000)$ en los 150 países analizados; no obstante, se observa que el ICB es más estricto en la clasificación de países con bajos valores del índice (para profundizar en este análisis, véase Muñoz y Torres 2010). Consideramos el ICB más adecuado por incluir una variable de salud reproductiva (de la que carece el IDH) y por no incluir, como sí hace el IDH, un indicador de renta (que no siempre representa cobertura de NSB, lo que puede distorsionar los datos). A pesar de ello, solo se dispone de datos del ICB a partir de 2007, por lo que finalmente se ha seleccionado el $\mathrm{IDH}^{5}$ para el análisis, ya que es el que presenta mayor volumen de datos disponibles para el periodo considerado. En cualquier caso, este inconveniente que presenta el IDH como indicador de cobertura de las NSB, quedará subsanado en el análisis sectorial, para el que se tomarán indicadores específicos para cada sector.

Si analizamos la evolución de la AOD desembolsada, los principales países receptores de AOD total, en el período 2002-2010, son Iraq, Afganistán, Nigeria, China, Indonesia e India, los cuales acumulan un 30\% del total de la ayuda (la cual asciende a 595463,2 millones de USD).

En el caso de la AOD para SSB, los principales receptores, que acumulan el $30 \%$ de la ayuda son India, Kenia, Tanzania, Sudáfrica, Etiopía, Nigeria, Uganda y Mozambique. Para analizar si existen diferencias significativas entre el ranking de países receptores de AOD total y los receptores de AOD para SSB se calculó el coeficiente de correlación Rho de Spearman entre ambas variables, para un total de 157 países en desarrollo que habían recibido ayuda en el período de análisis. El coeficiente resultó igual a 0,881 y significativo al nivel 0,01 , por tanto, podemos afirmar que el ranking de los países receptores de AOD para SSB coincide, mayoritariamente, con el ranking de los países receptores de AOD total.

Si observamos la evolución de la ayuda en los principales países receptores podemos observar como la tendencia en la mayoría de ellos es creciente, salvo India que muestra una evolución más desigual. Sin embargo, si consideramos la totalidad de los países receptores podemos afirmar que existe una gran volatilidad de la ayuda, medida como el coeficiente de Variación de Pearson (su valor asciende en el período de análisis al $75 \%$ sobre la ayuda promedio para los paí-

\footnotetext{
${ }^{5}$ El IDH ha sufrido un cambio metodológico en su cálculo que afecta al índice de educación, pero tiene lugar en el año 2010 por lo que no afecta al periodo analizado, ya que se ha trabajado con datos de IDH correspondientes al periodo 2000-2009.
} 
ses receptores). Esta volatilidad es mayor en los países que reciben menor cuantía de ayuda, tal y como lo demuestra el valor del coeficiente de correlación Rho entre el ranking de los países por la volatilidad de la ayuda y por la AOD concedida para SSB (igual a -0,582).

Es destacable que la tendencia al crecimiento parece frenarse en el año 2010, lo que coincide con la perspectiva de que la mayoría de los países donantes van a recortar sus aportaciones para proyectos de cooperación, debido a la persistencia de la crisis económica y los ajustes presupuestarios de muchos de los países donantes.

Para analizar si la asignación geográfica de la AOD para SSB atiende al criterio de la necesidad del país receptor, se comparó la posición que ocuparían los países socios en cuanto a la AOD recibida para SSB a lo largo del período analizado, desde el año 2002 al 2010, con la posición que ocuparían según el valor de su IDH durante los años previos al de la concesión de la ayuda. La matriz de correlaciones Rho de Spearman que compara ambos rankings (Tabla 7) arroja valores comprendidos entre $-0,65$ y $-0,75$, todos resultaron significativos al nivel 0,01 . El signo negativo indica que existe una relación inversa en las posiciones de los rankings, es decir, que los países que ocupan los primeros puestos por la cuantía de AOD recibida para SSB son los que ocupan los últimos puestos por valor de su IDH, es decir, que reciben más ayuda los que tienen peor IDH. La cuantía del coeficiente no es muy elevada, por lo que no existe una coincidencia mayoritaria entre ambos rankings de países, sin embargo, podemos comprobar que el coeficiente ha incrementado su valor con el transcurso de los años, lo que parece indicar una mayor atención a la necesidad del país en la asignación de la ayuda, lo que se puede valorar como una tendencia positiva.

Tabla 7

Coeficiente de correlación Rho de Spearman entre ranking de países socios según AOD recibida para SSB y su IDH

\begin{tabular}{|c|c|c|c|c|c|}
\hline \multirow{2}{*}{$\begin{array}{c}\text { Ranking } \\
\text { IDH }\end{array}$} & \multicolumn{5}{|c|}{ Ranking por AOD recibida para SSB } \\
\cline { 2 - 6 } & 2002 & 2004 & 2006 & 2008 & 2010 \\
\hline 2000 & $-0,661$ & $-0,692$ & $-0,684$ & $-0,721$ & $-0,753$ \\
\hline 2005 & & & $-0,657$ & $-0,682$ & $-0,734$ \\
\hline 2007 & & & & $-0,674$ & $-0,727$ \\
\hline 2009 & & & & & $-0,720$ \\
\hline
\end{tabular}

Fuente: Elaboración propia a partir de la base de datos CRS de la OCDE.

Sin embargo, hay que señalar que este análisis puede ocultar algunos datos relevantes, ya que aunque hay cierto grado de concordancia entre ayuda y situación del país, al realizar el análisis de los países peor valorados desde el punto de vista de su IDH, salen a la luz un grupo importante de países en situa- 
ción crítica respecto renta, educación y salud (con IDH por debajo de 0,3), como República del Congo, Níger y Burundi, entre otros, que están recibiendo cantidades ínfimas de AOD para SSB. Esta situación pone sobre la mesa la existencia de países infra-asignados con coberturas muy bajas en NSB como salud y educación, lo que debería implicar una reasignación de la AOD para SSB, destinando mayores cuantías a dichos países.

\subsection{Identificación de los principales receptores de AOD a SSB por sectores}

Siguiendo el modelo de asignación basada en la necesidad del receptor, habrá que seleccionar los Índices que sirvan de base para establecer el ranking sectorial de países; para ello, tomaremos el Índice de Educación (compuesto por la tasa de matriculación y tasa de alfabetización de adultos) para Educación Básica, el Índice de esperanza de vida al nacer para Salud Básica, la Prevalencia del VIH (\% de personas infectados por el VIH) para Población y Salud Reproductiva (ya que casi $3 / 4$ partes de la AOD en este sector se concentra en ayuda para el control del VIH) y el porcentaje de población con acceso a agua potable, para el sector de Saneamientos y Agua Potable.

\subsubsection{Análisis de los receptores de AOD en Educación Básica}

Respecto a la AOD en Educación básica se ha duplicado a lo largo del período, pasando de un volumen de AOD de 1638 millones de USD a 3644 millones de USD. Por países, existe gran concentración de la AOD en educación básica, ya que menos del 7\% de los países (India, Bangladesh, Afganistán, Pakistán, Egipto, Etiopia, Mozambique, Indonesia, Mali, Tanzania, Burkina Faso, Mayotte y Uganda) concentra el $50 \%$ de la ayuda. Asimismo, los destinatarios de la AOD son en su mayoría países con un índice educativo bajo, por lo que parece que la ayuda en educación básica está bien orientada a la necesidad del receptor. No obstante, hay que seguir trabajando en este sentido pues aún hay países con un IDE muy bajo que perciben poca cuantía de ayuda para educación. De los catorce países con el Índice de Desarrollo Educativo, IDE, por debajo de 0,300 (crítico), sólo cuatro de ellos están entre los donantes que acumulan el $50 \%$ de la ayuda.

Para comprobar estadísticamente si realmente los países donantes para Educación básica atienden al criterio de la necesidad de los países receptores en la orientación de su ayuda, se comparó el ranking de los países receptores por la cuantía de AOD recibida para Educación básica con el ranking de dichos países por el valor de su IDE. El coeficiente de correlación Rho de Spearman fue significativo y osciló entre el valor de $-0,5$ y $-0,6$. El signo negativo muestra que la relación entre las posiciones de los rankings es inversa, por tanto a mayor valor del IDE del país receptor menor cuantía recibe de AOD para Educación básica, sin embargo la relación entre ambos rankings no es fuerte, lo que corrobora la 
afirmación anterior de que aún hay que reorientar la ayuda para atender mejor a la necesidad del país receptor.

\subsubsection{Análisis de los receptores de AOD en Salud Básica}

En cuanto a la AOD en Salud Básica, también presenta una tendencia creciente, triplicándose en el periodo considerado, pasando de 2121 a 6646 millones de USD. Este incremento corresponde, sobre todo, al crecimiento espectacular de la ayuda multilateral a este sector (pasando de 483 a 3440 millones de USD).

Si analizamos el reparto por países, al igual que en educación, la ayuda está muy concentrada, ya que aproximadamente el $7 \%$ de los países (Iraq, India, Afganistán, Tanzania, Etiopia, Nigeria, República Democrática del Congo, Kenia, Zambia, Pakistán, Indonesia, Mozambique y Sudán) reciben el 50\% de la ayuda, con muchos países comunes en ambos sectores. Sin embargo, existen diferencias en cuanto a la cobertura en salud (frente a educación) de los principales países socios, ya que sólo 4 de los 14 principales receptores sitúan su Índice de salud por debajo de 0,5 . De los 23 países con un índice de salud bajo sólo 4 figuran entre los principales receptores. Como demuestra la posición de Iraq, en ocasiones, priman en la asignación de la ayuda otras consideraciones distintas a la necesidad, como por ejemplo las de naturaleza política. Para ratificar dicha afirmación se compararon los rankings de la posición de los países receptores por la cuantía de AOD recibida para Salud básica y sus valores del componente IDS del IDH y, efectivamente, los valores del coeficiente Rho de Spearman fueron muy bajos (entre $-0,15$ y $-0,16$ ) y no significativos. Por tanto, el sector de Salud básica, ha mostrado un importante desacuerdo entre la orientación de la ayuda y la necesidad del receptor.

\subsubsection{Análisis de los receptores de AOD en Población y Salud Reproductiva}

Este epígrafe es el que ha manifestado el mayor crecimiento en el periodo estudiado, pasando de 2277 millones de USD a 9653 millones de USD. Si analizamos por países, observamos que la ayuda está aún más concentrada que en educación y salud básica, repartiéndose menos del $5 \%$ de los países (Sudáfrica, Kenia, Nigeria, Uganda, Tanzania, Etiopía, Mozambique, Zambia e India) el $50 \%$ de la AOD en Población y Salud Reproductiva. Si analizamos el indicador seleccionado para medir la necesidad de este epígrafe, la prevalencia del VIH (medida como porcentaje de población entre 15 y 49 años infectada con VIH), en los países que más ayudan reciben, se observan algunos, como Sudáfrica y Mozambique que efectivamente presentan altos valores del indicador. Sin embargo, hay países con alta prevalencia, entre 4 y $26 \%$, ausentes entre los primeros receptores de ayuda: Lesoto $(23,3)$, República Centroafricana (6,3), Gabón (6), Camerún $(5,2)$ y República del Congo $(3,6)$, entre otros. El coeficiente Rho 
de Spearman tomó signo positivo, lo que indica que a mayor prevalencia mayor ayuda, aunque el valor osciló en torno al $0,4-0,5$, por lo que no hay un fuerte acuerdo entre los rankings de destino y necesidad.

\subsubsection{Análisis de los receptores de AOD en Agua Potable y Saneamientos Básicos}

Agua Potable y Saneamientos básicos es el sector con menor peso específico en la AOD en SSB de los cuatro analizados. Llega a triplicarse en el periodo analizado, pasando de los 538 en 2002 a los 1331 millones del año 2010. Respecto a la concentración de la AOD en Agua Potable y Saneamientos Básicos por países, aunque hay algo más de dispersión de la ayuda que en el resto de sectores, sigue existiendo una gran concentración, el $50 \%$ de la ayuda para el $9 \%$ de los países.

Con respecto a la necesidad de los países receptores, al comparar el ranking de los países por AOD recibida para agua y el indicador seleccionado (porcentaje de población con acceso a agua potable), el coeficiente Rho de Spearman tomó valores entre $-0,5$ y $-0,65$, lo que indica que a mayor porcentaje de acceso a agua potable menor AOD recibida, lo cual es lógico según el criterio de necesidad, aunque la relación no es muy fuerte, por lo que la ayuda tendrá que ir avanzando más en ese sentido para lograr un mayor grado de acuerdo entre ambos rankings.

\section{CONCLUSIONES}

El estudio revela que la ayuda a SSB ha incrementado de forma notable en la última década, lo cual es positivo, ganando peso el sector de Población y Salud reproductiva en detrimento de Educación y Salud básica. Tan solo tres países donantes, EE.UU., Japón y Alemania concentran más del 50\% de la AOD a $\mathrm{SSB}$, aunque por nivel de compromiso a la cabeza estarían países como Holanda, Luxemburgo y Bélgica. Por receptores, también se observa la concentración en la ayuda en los primeros puestos, recibiendo un 30\% de la ayuda el 5\% de los países socios (India, Kenia, Tanzania, Sudáfrica, Etiopía, Nigeria, China e Indonesia)

El análisis realizado demuestra que el compromiso $20 / 20$ no se está cumpliendo en la mayoría de los países donantes, a pesar de que parece claro que la cobertura universal de las NSB pasa, entre otros factores, por el cumplimiento de este acuerdo. En el caso de la ayuda multilateral, sin embargo, si se está destinando el $20 \%$ de la ayuda para SSB, probablemente las organizaciones multilaterales deciden el destino de la ayuda sin tantas limitaciones por intereses económicos, políticos o históricos como sucede en la ayuda bilateral. Respecto al grado de concordancia entre la asignación de la ayuda y la necesidad del receptor, podemos afirmar que para SSB es moderada (atendiendo al análisis de 
ranking AODSSB-IDH, el coeficiente Rho es -0,7), apreciándose una mejora en su valor para los últimos años; sin embargo, aún existen países en situación crítica (con su IDH por debajo de 0,3 ) que reciben cantidades mínimas de ayuda (República del Congo, Níger, Burundi, etc.). En el análisis sectorial el grado de acuerdo es más bajo, (todos los coeficientes Rho entre 0,5 y 0,6 ), especialmente en el caso de salud básica, en el que prácticamente no hay acuerdo entre necesidad y asignación de la ayuda. En todos los sectores se identifican países que a pesar de tener indicadores muy bajos o críticos, están prácticamente excluidos de la ayuda. Por tanto, el análisis pone de manifiesto, una vez más, que la asignación de la ayuda para SSB no siempre atiende a la necesidad del país receptor, revelando la existencia de países infra-asignados, tanto a nivel agregado en SSB, como a nivel sectorial. Por otra parte, los datos demuestran una gran volatilidad de la ayuda, que impide a los receptores acometer proyectos a largo plazo, que les garantice una mejor cobertura de las necesidades sociales básicas.

La situación de la Ayuda Oficial al Desarrollo está en un momento crítico, derivado por un lado, de la crisis internacional que está provocando una drástica reducción de la partida de cooperación de los presupuestos en los países donantes, y por otro, la llamada "fatiga de la ayuda" por el cuestionamiento de su eficacia. La situación exige muchas dosis de colaboración y armonización de políticas de donantes y socios, y una orientación geográfica y sectorial, de modo que la disminución en cuantía se vea compensada con la mejor asignación. Quizá ha llegado el momento de incluir en la agenda post-2015 enfoques de la ayuda adaptados a las necesidades específicas, locales y sensibles al contexto, y cuya efectividad depende en gran medida de la voluntad de colaboración real y no, únicamente, de la firma de acuerdos entre países en desarrollo y países desarrollados que no pasan de ser firmas estampadas en el papel.

\section{REFERENCIAS BIBLIOGRÁFICAS}

BARRO, R. (2007), "Desigualdad y crecimiento: revisión". Boletín informativo Techint 324, BID. http://www.iadb.org/intal/intalcdi/PE/2008/01100.pdf (Consulta Octubre 2012)

BURNSIDE, C. y DOLLAR, D. (2000), "Aid, Policies, and Growth". American Economic Review 90 (4) pp. 847-868.

COMITÉ DE AYUDA AL DESARROLLO (CAD). Base de datos on line: http://stats.oecd.org/Index.aspx?datasetcode=CRS1\# (Consulta Marzo 2012)

EASTERLY, W., LEVINE, R., ROODMAN, D. (2004), "New data, new doubts: A comment on Burnside and Dollar's aid, policies, and growth". American Economic Reviewi 94, pp. 774-780. 
FONTELA, E., y GUZMAN, J. (2003). "La teoría circular del desarrollo. Un enfoque complejo". Estudios de Economía Aplicada, vol. 21, nº02, pp.221-242.

FOSU, A.K. (2010), Inequality, income and poverty: Compartive global evidence. Brooks World Poverty Institute, Manchester.

HANSEN, H. y TARP, F. (2000), "Aid effectiveness disputed", Journal of International Development 12 (3), pp. 375-398.

HICKS, N. AND P. STREETEN (1979). "Indicators of Development: The Search for a Basic Needs Yardstick". World Development, 7, 567-580.

IGLESIA-CARUNCHO, M. (2011), Politica exterior y política de cooperación: ¿amistades peligrosas? Fundación Carolina, East Sussex.

McGILLIVRAY, M. (1991). "The Human Development Index: Yet Another Redundant Composite Development Indicator?" World Development, 19, 1461-8

MEHROTRA, S., VANDEMOORTELE J. y DELAMONICA, E. (2000), ¿Servicios básicos para todos? El gasto público y la dimensión social de la pobreza. Centro de Investigaciones Innocenti de UNICEF, Florencia.

MOSLEY, P. (1987), Foreign aid, its defense and reform. United States: University Press of Kentucky.

MUÑOZ, Y. (2006), "Las necesidades sociales básicas en el marco de las teorías del desarrollo", III Congreso Universidad y Cooperación al Desarrollo, Madrid, Abril de 2006 (Libro de resúmenes, volumen 1)

MUÑOZ, Y. y TORRES, M. (2010), "Cómo medir la cobertura en necesidades sociales básicas: IDH vs ICB", Anales de Economía Aplicada 2010, AsepeltDelta.

MUÑOZ, Y. y TORRES, M (2012), "La Ayuda Oficial al Desarrollo en Servicios Sociales Básicos", I Congreso Internacional de Estudios de Desarrollo, REEDES, Santander. http://congresoreedes.unican.es/actas/PDFs/2.pdf

NACIONES UNIDAS (1986), Declaración sobre el derecho al desarrollo. http://www2.ohchr.org/spanish/law/desarrollo.htm (Consulta Enero 2012)

NACIONES UNIDAS (2000), Objetivos del Milenio

NACIONES UNIDAS, ASAMBLEA GENERAL (2000), Nuevas iniciativas en pro del desarrollo social.

NACIONES UNIDAS, ASAMBLEA GENERAL (2005), Documento Final de la Cumbre 2005.

NACIONES UNIDAS (2010), Cumbre sobre cumplimiento de los ODM. http://www.un.org/es/mdg/summit2010/ (Consulta Abril 2012)

NUSSBAUM, M. (2007), Las fronteras de la justicia: consideraciones sobre la exclusión. Paidós, Barcelona.

NUSSBAUM, M. (2012), Crear capacidades: propuesta para el desarrollo humano. Paidós, Barcelona.

OCDE (2005). Declaración de París sobre la Eficacia de la Ayuda al Desarrollo. http://www.oecd.org/dataoecd/53/56/34580968.pdf (Consulta Febrero 2012) 
OCDE (2006), Creditor Reporting System. Aid Activities for Basic Social Services in 2004 (www.Source-OECD.org).

OCDE (2008). Programa de Acción de Accra. http://www.oecd.org/dataoecd/ 53/56/34580968.pdf (Consulta Febrero 2012)

OCDE (2011). Alianza de Busan para la cooperación eficaz al desarrollo. http://www.oecd.org/dataoecd/54/36/49650200.pdf (Consulta Febrero 2012)

OCDE (2012). Base de datos on line: http://www.oecd.org/document/ 0,3746,en_2649_201185_46462759_1_1_1_1,00.html (Consulta Marzo 2012)

PENA-TRAPERO, B. (2009), "La medición del Bienestar Social: una revisión crítica". Estudios de Economía Aplicada, vol. 27-2, pp. 299-324.

PNUD (2012), Base de datos on line: http://hdr.undp.org/es/estadisticas/ (Consulta Marzo 2012)

RAVALLION, M. (2000), "Growth, Inequality and Poverty: Looking Beyond Averages". Development Research Group, Banco Mundial, Washington.

RIDDELL, R.C. (2007), Does Foreign Aid Really Work? Oxford University Press, New York.

SACHS, J. (2005), The end of poverty. Penguin Press, London.

SOTILLO, J.A. (2011), El sistema de cooperación para el desarrollo. Catarata, Madrid.

TEZANOS, S. (2008), "Modelos teóricos y empíricos de asignación geográfica de la ayuda al desarrollo". Principios: estudios de economía aplicada 10, pp. 5-39

TEZANOS, S. (2011), "Más allá de 2015: Objetivos de Desarrollo del Milenio y desafíos para la nueva agenda internacional de desarrollo". Sistema 220, pp. 33-58.

UNCETA, K., MARTíNEZ, M.J. y ZABALA, I. (2012), "La crisis de la Cooperación al Desarrollo: los ODM, la Agenda de Desarrollo y el papel de la AOD”. Boletín de recursos de información $n^{\circ}$ 31. Centro de Documentación Hegoa, Universidad del País Vasco.

VANDEMOORTELE, J. (2004), "Los ODM y las políticas a favor de los pobres: Relacionados pero no sinónimos". Centro Internacional de Pobreza, Working paper \#3, Brasilia.

VANDEMOORTELE, J. (2009), "Ajuste de las estadísticas nacionales para medir las desigualdades". Redes HDR $n^{\circ} 26$, PNUD.

VANDEMOORTELE, J. (2010), "Cambiar el curso cambiando el discurso sobre Ios ODM". ARI No 132. REAL INSTITUTO ELCANO, MADRID.

VERES, E.J. (2006). "Diseño de un índice para la medición del desarrollo humano". Estudios de Economía Aplicada, vol. 24, n 3, pp.1013-1042.

WILLIAMSON, J.G. (2003), "From reform agenda to damaged brand name - a short history of the Washington Consensus and suggestions for what to do next". Finance and Development, September, pp. 11-13. 